\title{
Keynes, Uncertainty and Interest Rates
}

\author{
Brian Weatherson
}

\begin{abstract}
Uncertainty plays an important role in The General Theory, particularly in the theory of interest rates. Keynes did not provide a theory of uncertainty, but he did make some enlightening remarks about the direction he thought such a theory should take. I argue that some modern innovations in the theory of probability allow us to build a theory which captures these Keynesian insights. If this is the right theory, however, uncertainty cannot carry its weight in Keynes's arguments. This does not mean that the conclusions of these arguments are necessarily mistaken; in their best formulation they may succeed with merely an appeal to risk.

"Employment was a problem because investment was; and investment was problematic because of the uncertainty of its return." (Shapiro, 1997, 83)
\end{abstract}

Keynes clearly saw an important role for uncertainty in his General Theory. However, few contemporaries agreed with him, and subsequent 'Keynesians' generally obliterated the distinction between risk and uncertainty. In part this was caused by Keynes's informal presentation of his views on uncertainty in The General Theory. This paper has two aims. The first is to sketch a formal theory of uncertainty which captures Keynes's insights about the risk/uncertainty distinction. I argue that the theory of imprecise probabilities developed in recent years best captures Keynes's intuitions about uncertainty. In particular this theory provides a formal distinction between risk and uncertainty, and allows for an analysis of Keynes's 'weight' of arguments. However, the second aim is to show that if this is right then Keynes was wrong to draw the economic consequences of uncertainty that he did. In broad terms, I argue that uncertainty is economically impotent. It only has effects in conjunction with some other feature of models or the world, such as missing markets or agent irrationality. But these features plus the existence of risk are sufficient to get the conclusions Keynes wants. These conclusions of Keynes might be right, but if so they can be justified without reference to Keynesian uncertainty. At the end of the day, uncertainty is not as economically interesting as it appears.

\section{Imprecise Probabilities}

In the classical, or Bayesian ${ }^{1}$, model of rationality all rational agents have precise degrees of belief, or credences, in each proposition. There is a probability function

\footnotetext{
$\dagger$ Penultimate draft only. Please cite published version if possible. Final version published in Cambridge Journal of Economics 26 (2002): 47-62.

${ }^{1}$ For this paper I follow Walley (1991) in describing those theorists who require that all agents have precise degrees of belief and these degrees form a probability function as Bayesians. There is some dispute
} 
$B e l$ such that for any proposition $A$, there is a number $\operatorname{Bel}(A)$. So if an agent believes $p$ to degree $x$ she believes $p$ to degree $1-x$. This is appropriate for some propositions. For example, if $p$ is a proposition about the decay of an atom with known half-life, or about any event with a known objective chance and hence subject to risk and not uncertainty, the agent's credences should reflect the chances. Since chances are precise and form a probability function, the credences will also have these properties. The Bayesian theory assumes that all situations can be treated by analogy with these.

As Keynes pointed out in the famous $Q J E$ article (Keynes, 1937b), this analogy is clearly mistaken. When $p$ is about the price of copper in thirty years, we do not know the chance that $p$ will be true. And we do not have enough information to form a precise credence. As Keynes had argued in his Treatise on Probability sixteen years earlier, attempts to avoid this problem by appeal to a Principle of Indifference lead to contradiction. In The General Theory he noted that he still approved of this little argument (Keynes, 1936, 152). Hence Bayesians have no way of representing our ignorance in uncertain situations. They say that all rational agents have a precise epistemic attitude towards each proposition, believing it to some precise degree, whereas ignorance consists in not having such a precise attitude.

The theory of imprecise probabilities avoids all of these difficulties. The theory is quite old, dating back to work by Gerhard Tintner (1941) and A. G. Hart (1942), but has only received extensive consideration recently. The best modern summaries are by the philosopher Isaac Levi (1980) and the statistician Peter Walley (1991). There are minor differences, but the theory I shall give captures all the common ingredients. According to Bayesians, states of rational agents are represented by a single probability function $P r$, in the imprecise theory they are represented by a set of probability functions $S$. The agent's credence in $p$ is vague over the set of values that $\operatorname{Pr}(p)$ takes for $\operatorname{Pr} \in S$. In the extreme case, for every $x \in[0,1]$ there will be a $\operatorname{Pr} \in S$ such that $\operatorname{Pr}(p)=x$. This represents almost total ignorance about $p$. The set $S$ is called the 'representor' of the agent whose credences it represents.

It is important to stress what $S$ represents, because there has been some confusion over this ${ }^{2}$. The $\operatorname{Pr}$ do not represent the agent's hypotheses about the correct distribution of objective chances. I use the phrase 'objective chance', or just 'chance', to refer to a property that plays a certain role in fundamental physics, the property which makes it the case that the whirrings of atoms in the void is indeterminate. Modern physics, or at least the most popular versions of it, teaches that chance infects all fundamental physical events. These chances fulfill all the properties that anyone has ever wanted in probabilities. They reflect long-run frequencies of repeated events, they put restrictions on reasonable degrees of belief, they can be properly applied to single cases, and so on. If all fundamental physical events are chance events, then arbitrary Boolean combinations of fundamental physical events should also, presumably, be chance events. But any event whatsoever is some combination of fundamental physical events, though for many it may not be clear which combination. So baseball

as to the accuracy of this labelling, particularly as some paradigm case Bayesians, such as Jeffrey (1983) and van Fraassen (1990), accept that degrees of belief can be vague. However, there is probably no other name as convenient or as recognisable.

${ }^{2}$ See, for example, Gärdenfors and Sahlin (1982), Levi (1982). 
games, romantic affairs and stock market movements are all chance events in this sense, even though they are not, for instance, repeatable events. Of course, trying to predict these using the laws of physics will be even less productive than trying to predict them using the methods we currently have available. Saying where all the atoms, or quarks, currently are is humanly impossible, and perhaps theoretically impossible as well. Even allowing for this, computing where they will move before they get there is beyond the capacity of any possible machine.

I distinguish between a situation where the agent does not know the objective chance of some proposition, and a situation where the agent has no precise credence in that proposition. An agent can have a precise credence in $p$ without knowing its objective chance. If the agent believes that a certain number of chance distributions are possible, and gives each of them a precise credence, this entails she has a precise credence in each event. (Imagine we see a fair coin be tossed, and land, but do not see how it falls. The objective chance that it shows heads is either one, if it does, or zero, otherwise. But the appropriate credence in the proposition, the coin has landed heads, is one half.) Rather the $\operatorname{Pr}$ represent the precise credence distributions that are consistent with real imprecise distribution. For example, for some rational agent, and some proposition $p$, the agent's epistemic state will determine that she believes $p$ to a greater degree than 0.2 , and a lesser degree than 0.4 , but there will be no more facts about the matter. (In this case $S$ will include a function $\operatorname{Pr}$ such that $\operatorname{Pr}(p)=x$ for each $x \in[0.2,0.4]$.) If we ask her whether she thinks $p$ is more likely than some proposition, call it $q$, which she believes to degree 0.3 , she will not be able to say one way or the other. And this is not just because she lacks rationality or powers of introspective observation. It is no requirement of rationality that she believe $p$ is more likely, less likely or equally likely than $q$ As Levi and Walley have pointed out, the Bayesian arguments purporting to show this is a constraint on rationality have been hopelessly circular.

The reasons for wanting to be able to represent uncertainty were stressed by Keynes, and are generally well known. Before showing why this theory captures Keynes's intuitions about uncertainty, I will briefly mention two nice formal features of the theory of imprecise probabilities. On many theories of uncertainty, particularly those that represent uncertain agents as having interval valued degrees of belief, it is hard to explain comparative statements, like " $p$ seems more likely to me than $q$ ". These comparatives are crucial to our everyday practices of probabilistic reasoning. We say $p$ is more probable than $q$ according to $S$ iff for all $\operatorname{Pr} \in S, \operatorname{Pr}(p)>\operatorname{Pr}(q)$. This lets us say, as seems right, that $A$ is more probable than $A \wedge B$ for almost all propositions $A, B$.

The second formal advantage is that we now have a simple way to update epistemic states on receiving new evidence. Let $S$ be the agent's current representor, and the new evidence be $e$. Then the updated representor, $S_{e}$ is given as follows:

$$
S_{e}=\{\operatorname{Pr}(\bullet \mid e): \operatorname{Pr} \in S\}
$$

That is, we just conditionalise every probability function in $S$. Again, updating has proven problematic for some approaches to uncertainty. The theory of evidence 
functions, developed by Dempster (1967) and Shafer (1976) allows that an agent can know that if either $e$ or $\neg e$ comes in as evidence, their credence in $p$ will rise. This seems absurd; we can know before an experiment that whatever happens we'll be more confident in $p$ than we are now.

To take a famous example, three prisoners $X, Y$ and $Z$ are about to be exiled to Elba. The governor decides on a whim that he will pardon one, and casts a fair die to choose which. He tells the guards who is pardoned, but instructs them not to tell the prisoners yet. $X$ pleads futilely with his guard, and finally asks, "Can you tell me the name of one of the others who won't be pardoned." The guard, realising this will not reveal $X$ s fate, agrees to answer. $X$ thinks that if $Y$ is pardoned, the guard will say $Z$, so there is at least a one-third probability of that. And if $Z$ is pardoned, the guard will say $Y$, so there is also at least a one-third probability of that. But if he is pardoned, what the guard will have to decide what to say, and we can't make probability judgements about free human decisions. On the Dempster-Shafer theory, the probability of $X$ being freed is one-third, but the probability of $X$ being freed and the guard saying $Y$ goes to Elba is zero, and the probability of $X$ being freed and the guard saying $Z$ goes to Elba is zero. This is just a standard failure of additivity, and not at all objectionable. The problem is that when the guard says that $Y$ will go to Elba, or that $Z$ will go to Elba, the probability of $X$ being freed rises to one-half. (I will not go through the mathematics here, because it can be found in any book on the Dempster-Shafer theory. See, for example, Walley (1991) or Yager et al. (1994).) Since $X$ did not learn about his chances of freedom, this seems like a rather odd result. The theory of imprecise probabilities avoids this problem. It can be easily shown that on this theory for any evidence $e$ if the probability of $p$ given $e$ is greater than the probability of $p$, then the probability of $p$ given $\neg e$ is less than the probability of $p$. (Again Walley (1991) contains the proof.)

\section{Keynes and Imprecise Probabilities}

Obviously enough, this is not the theory that Keynes formally endorses, either in his Treatise on Probability (Keynes, 1921) or his economic writings. Nevertheless, I think it is an important theory for understanding Keynes's use of uncertainty. This is because it, and it alone, captures all of the underlying motivations of Keynes's theory of uncertainty. Hence any economic consequences of uncertainty Keynes wants to draw will have to be derivable from this theory.

I have so far spoken blithely of 'Keynes's theory of uncertainty', implicitly assuming there is such a unique theory. In recent years a number of authors (e.g. Runde (1994a); Davis (1994); Coates (1996); Bateman (1996) have questioned this assumption, saying that Keynes changed his theory between the writing of the Treatise on Probability and The General Theory. I will not deal directly with such criticisms here for a number of reasons. First, the main dispute is over whether probabilities are given by logic or are 'merely subjective', and that debate is independent of the debate about the effects of allowing imprecise probabilities. Secondly, there are obvious space constraints. Many of these alternative interpretations were put forward in book length arguments, and a fair response to them would not be short. Thirdly, and 
perhaps most importantly, I take it that the methodological game here is inference to the best explanation. Whatever criticisms I make of others' interpretations would be rather weak unless I showed that some other overall story was more persuasive. And if I come up with a more persuasive story here criticisms of their accounts will be slightly redundant. So I hope the reader at least permits the indulgence of setting out a theory of Keynes's ideas predicated on this rather controversial assumption.

In the Treatise on Probability (Keynes (1921), hereafter TP) Keynes says that probability is essentially a property of ordered pairs of propositions, or what he calls arguments. He writes $p / q=\alpha$, for the probability of hypothesis $p$ on evidence $q$ is $\alpha$. Now this value $\alpha$ is rather unusual. It sometimes is a number, but sometimes not; it sometimes can be compared to all numbers, but sometimes not; it sometimes can be compared to other probability values such as $\beta$, but sometimes not and it can enter into arithmetic operations. As a consequence probabilities are subject to all the usual rules of the classical probability calculus. For example, whenever $p$ and $r$ are inconsistent, then $(p \vee r) / q=p / q+r / q$ always holds, even when none of these values is numerical.

These five properties are rather perplexing. Indeed, Keynes's failure to explain or justify them fully is one of the main criticisms that Ramsey (Ramsey, 1926, 161-6) launches at Keynes's theory. But on this theory they all fall out as consequences of our definitions. If $p / q=\alpha$ then $\alpha$ will be numerical iff there is some $x$ such that for all $\operatorname{Pr} \in S, \operatorname{Pr}(p \mid q)=x$. Similarly $\alpha>y$, for real valued $y$, iff $\operatorname{Pr}(p \mid q)>y$ for all $\operatorname{Pr} \in S$. A similar definition holds for $\alpha<y$ and $\alpha=y$, from which it can be seen that it is possible that $\alpha$ is neither greater than, less than, nor equal to $y$. If none of these hold we say that $\alpha$ and $y$ are incomparable. If $p / q=\alpha$ and $r / s=\beta$ then $\alpha>\beta$ iff for all $\operatorname{Pr} \in S, \operatorname{Pr}(p \mid q)>\operatorname{Pr}(r \mid s)$. Again similar definitions of less than and equal to apply, and the consequence of all these is that sometimes $\alpha$ and $\beta$ will be comparable, sometimes not.

Ramsey is right to question the intelligibility of Keynes's use of addition and multiplication. We know what it means to add and multiply numbers, but we have no idea what it is to add or multiply non-numerical entities. However, on this theory addition and multiplication are perfectly natural. Since we represent $\alpha$ and $\beta$ by sets, generally intervals, then $\alpha+\beta$ and $\alpha \dot{\beta}$ will be sets. They are defined as follows. Again let $p / q=\alpha$ and $r / s=\beta$.

$$
\begin{aligned}
\alpha+\beta & =\{x: \exists \operatorname{Pr} \in S(\operatorname{Pr}(p \mid q)+\operatorname{Pr}(r \mid s)=x)\} \\
\alpha \dot{\beta} & =\{x: \exists \operatorname{Pr} \in S(\operatorname{Pr}(p \mid q) \operatorname{Pr}(r \mid s)=x)\}
\end{aligned}
$$

These definitions are natural in the sense that we are entitled to say that the ' + ' in $\alpha+\beta$ means the same as the ' + ' in $2+3$. And the definitions show why Keynes's $\alpha$ 's and $\beta$ 's will obey the axioms of the probability calculus. Even if $p / q$ and $\neg p / q$ are nonnumerical, $p / q+\neg p / q$ will equal $\{1\}$, or effectively 1 . So we have something like the additivity axiom, without its normal counterintuitive baggage. The main problem with additivity is that sometimes we may have very little confidence in either $p$ or $\neg p$, but we are certain that $p \vee \neg p$. If we measure confidence by the lower bound on 
these probability intervals, this is all possible on our theory. Our technical apparatus removes much of the mystery behind Keynes's theory, and fends off an important objection of Ramsey's.

The most famous of Keynes's conceptual innovations in the TP is his introduction of 'weight'. He does this in the following, relatively opaque, paragraph.

As the relevant evidence at our disposal increases, the magnitude of the probability of the argument may either decrease or increase, according as the new knowledge strengthens the unfavourable or the favourable evidence; but something seems to have increased in either case, - we have a more substantial basis upon which to rest our conclusion. I express this by saying that an accession of new evidence increases the weight of an argument. New evidence will sometimes decrease the probability of an argument, but it will always increase its 'weight' (Keynes, 1921, 77, italics in original).

The idea is that $p / q$ measures how the evidence in $q$ is balanced between supporting $p$ and supporting $\neg p$. The concept of weight is needed if we want to also know how much evidence there is. Note that weight only increases when relevant evidence comes in, not when any evidence comes in. The weight of the argument from my evidence to "Oswald killed JFK" is not increased when I discover the Red Sox won last night.

The simplest definition of relevance is that new evidence $e$ is irrelevant to $p$ given old evidence $q$ iff $p / q \wedge e)=p / q$, and relevant otherwise. Now there is a problem. Two pieces of evidence $e_{1}$ and $e_{2}$ can be irrelevant taken together, but relevant taken separately. For a general example, let $e_{1}$ be $p \vee r$ and $e_{2}$ be $\neg p \vee r$, for almost any proposition $r$. If I receive $e_{1}$ and $e_{2}$ sequentially, the weight of the argument from my evidence to $p$ will have increased twice as I receive these new pieces of evidence. So it must be higher than it was when I started. But if I just received the two pieces of evidence at once, as one piece of evidence, I would have properly regarded it as irrelevant. Hence the weight in question would be unchanged. So it looks as if weight depends implausibly not on what the evidence is, but on the order in which it was obtained.

Keynes avoids this implausibility by tightening up the definition of irrelevance. He says that $e$ is irrelevant to $p / q$ iff there are no propositions $e_{1}$ and $e_{2}$ such that $e$ is logically equivalent to $e_{1} \wedge e_{2}$ and either $e_{1}$ or $e_{2}$ is relevant to $p / q$. Unfortunately, as I noted in the previous paragraph for virtually any such evidence proposition there will be such propositions $e_{1}$ and $e_{2}$. This was first noticed by Carnap (1950). Keynes, had he noticed this, would have had three options. He could conceded that everything is relevant to everything, including last night's baseball results to the identity of Kennedy's assassin; he could have conceded that the order in which evidence appears does matter, or he could have given up the claim that new relevant evidence always increases the weight of arguments.

The last option is plausible. Runde (1990) defends it, but for quite different reasons. He thinks weight measures the ratio of evidence we have to total evidence we 
believe is available. Since new evidence might lead us to believe there is much more evidence available than we had previously suspected, the weight might go down. I believe it holds for a quite different reason, one borne out by Keynes's use of uncertainty in his economics. In The General Theory (Keynes (1936), hereafter GT) Keynes stresses the connection between uncertainty and 'low weight' (GT: 148n). If we regard $p$ as merely risky the weight of the argument from our evidence to $p$ is high, if we regard $p$ as uncertain the weight is low. In the Quarterly Journal of Economics article he argues that gambling devices are, or can be thought to be, free of uncertainty, whereas human actions are subject to uncertainty. So the intervention of humans can take a situation from being risky to being uncertain, and hence decrease the weight in question.

For example, imagine we are playing a rather simple form of poker, where each player is dealt five cards and then bets on who has the best hand. Before the bets start, I can work out the chance that some other player, say Monica, has a straight. So my credence in the proposition Monica has a straight will be precise. But as soon as the betting starts, my credence in this will vary, and will probably become imprecise. Do those facial ticks mean that she is happy with the cards or disappointed? Is she betting high because she has a strong hand or because she is bluffing? Before the betting starts we have risk, but no uncertainty, because the relevant probabilities are all known. After betting starts, uncertainty is rife.

The poker example supports my analysis of weight. If weight of argument rises with reduction of uncertainty, then in some rare circumstances weight of arguments decreases with new evidence. Let $\left[x_{1}, x_{2}\right]$ be the set given by $\{x: \operatorname{Pr}(p \mid q)=x\}$ for some $\operatorname{Pr} \in S\}$, where $S$ is the agent's representor. Then the weight of the argument from $p$ to $q$, for this agent, is $1-\left(x_{2}-x_{1}\right)$. That is, the weight is one when the agent has a precise degree of belief in $p$, zero when she is totally uncertain, and increasing the narrower the interval $\left[x_{1}, x_{2}\right]$ gets. Now in most cases new relevant evidence will increase the weight, but in some cases, like when we are watching Monica, this will not happen. I follow Lawson (1985) in saying that $p$ is uncertain for an agent with evidence $q$ iff $p / q$ is non-numerical, i.e. iff the weight of the argument from $q$ to $p$ is less than one. Hence we get the connection between uncertainty and weight Keynes wanted. I also claim that the bigger $x_{2}-x_{1}$ is, the more $p / q$ is unlike a real number, the more uncertain $p$ is. Keynes clearly intended uncertainty to admit of degrees Keynes (1937b), so this move is faithful to his intent.

Keynes's theory of probability is based around some non-numerical values whose nature and behaviour is left largely unexplained, and a concept of weight which is subject to a telling and simple objection. Nevertheless, his core ideas, that probabilities can but need not be precise, and that we need a concept like weight as well as just probability, both seem right for more general reasons. Hence the theory here, which captures the Keynesian intuitions while explaining away his mysterious nonnumerical values and making the concept of weight more rigorous, looks to be as good as it gets for a Keynesian theory of uncertainty.

One particularly attractive feature of the account is how conservative it is at the technical level. We do not need to change our logic, change which things we think are 
logical truths, or which things follow from which other things, in order to support our account of uncertainty. This is in marked contrast to accounts based on fuzzy logic or on logics of vagueness. Not only are such changes in the logic unmotivated, they appear to lead to mistakes. No matter how uncertain we are about how the stock will move over the day, we know it will either close higher or not close higher; and we know it will not both close higher and not close higher. The classical laws of excluded middle and non-contradiction seem to hold even in cases of massive uncertainty. This seems to pose a serious problem for theories of uncertainty based on alternative logics. The best approach is one, like the theory here, which is innovative in how it accounts for uncertainty, and conservative in the logic it presupposes.

So as a theory of uncertainty I think this account has a lot to be said for it. However, it cannot support the economic arguments Keynes rests on it.

\section{The Economic Consequences of Uncertainty}

Uncertainty can impact on the demand for an investment in two related ways. First, it can affect the value of that particular investment; secondly, it can affect the value of other things which compete with that investment for capital. The same story is true for investment as a whole. First, uncertainty may reduce demand for investment directly by making a person who would otherwise be tempted to invest more cautious and hence reluctant to invest. Secondly, if this direct impact is widespread enough, it will increase the demand for money, and hence its price. But the price of money is just the market rate of interest. And the return that an investment must be expected to make before anyone, even an investor not encumbered by uncertainty, will make it is the rate of interest.

When uncertainty reduces investment by increasing interest rates, I will say it has an indirect impact on investment. Keynes has an argument for the existence of this indirect impact. First, he takes the amount of consumption as a given (GT: 245). Or more precisely, for any period he takes the amount of available resources that will not be allocated to consumption as a given. There are three possible uses for these resources: they can be invested, they can be saved as bonds or loans, or they can be hoarded as money. There are many different types of investment, but Keynes assumes that any agent will already have made their judgement as to which is the best of these, so we need only consider that one. There will also be many different length bonds which the agent can hold. So as to simplify the discussion, Keynes proposes just treating these two at a time, with the shorter length bond called 'money' and the longer length loan called 'debts' (GT: 167n). Hence the rate of interest is the difference between the expected return of the shorter bond over the life of the longer bond and the return of the longer bond. So the rate of interest that we are interested in need not be positive, and when the two bond lengths are short will usually be zero. However, it is generally presumed in discussions that the rate is positive. Now, Keynes assumes that an agent will only allocate resources to investment if investment looks to be at least as worthwhile as holding money, and at least as worthwhile as holding debts. In other words, he makes the standard reduction of $n$-way choice to 
a set of 2-way choices ${ }^{3}$. Usually if someone is of a mind to invest they will not favour holding money over holding debts. The only motivation for holding money, given positive interest rates, could be a desire to have accessible command over purchasing power, and investment foregoes that command. So in practice we only need look at two of the three possible pairwise choices here. Hence I will ignore the choice between investing and holding money, and only look at the money-debt choice and the debt-investment trade-off.

Holding a debt provides a relatively secure return in terms of money. Relatively secure because there is the possibility of default. In practice, this means that there is not a sharp distinction between debts and investments, rather a continuum with say government bonds at one extreme and long-term derivatives at the other. Some activities that have the formal structure of 'debts', like say provision of venture capital, will be closer to the investment end of the continuum. Unlike debts then, investments as a rule do not have a secure return in terms of money. In most cases they do not even have a precise expected return (GT: 149; Keynes (1937b, 113)). Keynes does not presume that this means that people never invest unless the expected return on the investment is greater than the expected (indeed, known) return on debts. $\mathrm{He}$ says explicitly that were this true then 'there might not be much investment'. Instead, he says that investment under uncertainty depends on 'confidence' (GT: 150). Therefore, the following looks compatible with his position.

Bayesians say that each gamble has a precise expected value. The expected return on a bet that pays $\$ 1$ if some fair coin lands heads is 50 cents. On this theory, expected values are imprecise, because probabilities are imprecise. Formally, say $E_{P r}(G)=\alpha$ means that the expected return on $G$ according to probability function $\operatorname{Pr}$ is $\alpha$. Roughly, the expected value for an agent of a gamble $G$ will be $\{x: \exists \operatorname{Pr} \in$ $\left.S:\left(E_{P r}(G)=x\right)\right\}$, the set of expected values of the bet according to each probability function in the agent's representor. Note that these are different from the possible outcomes of the bet. As we saw in the case of the coin, expected value can differ from any possible value of the bet. So let the expected value of inesting a certain sum be $[\alpha, \beta]$, and the expected value of buying a debt with that money be $\chi$. Then the agent will invest iff $(1-\rho) \alpha+\rho \beta \geq \chi$, where $\rho \in[0,1]$ measures the 'state of confidence. ${ }^{4}$ Now when a crisis erupts, $\rho$ will go to 0 , and investment will dry up. In such cases the decision theory is similar to the one advanced by Levi (1980), Strat (1990) and Jaffray (1994). Since we are interested in a theory of unemployment, we are primarily interested in the cases where $\rho$ is quite low, in which cases we can say uncertainty is reducing investment.

That last statement might seem dubious at face value. In part, what I mean by it is this. When $\rho$ is low the value of a set of bets will in general be more than the sum of the value of the bets taken separately. Because individual investors are

\footnotetext{
${ }^{3}$ Standard, but I bring it up because the modern theorist whose decision theory is closest to the one Keynes seems to adopt, Levi, explicitly rejects it.

${ }^{4}$ In case the reader fears I am being absurdly formal with an essentially informal idea, Keynes had such a variable, there described as measuring the 'state of the news', in early drafts, but it did not survive to the final stage. So my proposal is not a million miles from what Keynes intended merely by virtue of being algebraic.
} 
fearful of exposure to uncertainty, which is presumably what $\rho$ being low means, sets of investments which if undertaken collectively would be profitable (and everyone agrees that they would) will not be undertaken individually. This suggests a reason that theorists have thought government intervention might be appropriate in times of crisis. Alternatively, if $\rho$ is low then the value of an investment, how much we will be prepared to pay for it, will probably be lower than our best estimate of its expected return, assuming the latter to be near $(\alpha+\beta) / 2$.

I shall focus more closely on the indirect effects of uncertainty in section 5 . The central idea is that the rate of interest, being the price of money, is completely determined in the market for money. However, this market has some rather strange properties. After all, money is barren, and it can generally be traded for something that is not barren. So, as Keynes puts it, why would anyone 'outside a lunatic asylum', want it? Why would the demand for money not drop to zero as soon as the rate of interest is positive?

Because, partly on reasonable and partly on instinctive grounds, our desire to hold money as a store of wealth is a barometer of the degree of our distrust of our own calculations and conventions concerning the future ... The possession of actual money lulls our disquietude; and the premium which we require to make us part with money is the measure of the degree of our disquietude (Keynes, 1937b, 116).

Therefore, more uncertainty means more demand for money means higher interest rates. The rest of the story is standard. Even the confident agent will be disinclined to invest once the rate of interest rises. Using the little decision theory outlined above, more uncertainty means the gap between $\alpha$ and $\beta$ grows, which if $\rho$ is low will tend to reduce $(1-\rho) \alpha+\rho \beta$, the 'certainty equivalent' of the expectation of the investment's worth. On the other hand, uncertainty on the part of the community will tend, for similar reasons, to increase $\chi$. Either way, investment suffers, and hence so does employment.

\section{Uncertainty and Money}

There is something very odd about all that we have done so far. Agents react to uncertainty by making their returns measured in dollars more stable. However, in doing so they make their returns measured in any other good less stable. If you have no idea what the price of widgets will be in twelve months time, then holding only widgets increases the uncertainty about how many dollars you will be worth then. However, it makes you more certain about how many widgets you will be worth. Why this preference for money? We deserve an explanation as to why one kind of uncertainty is given such a central place and other kinds are completely ignored.

Keynes has one explanation. He argues, or perhaps assumes, essentialism about money. Indeed the title of chapter 17 of The General Theory is 'The Essential Properties of Interest and Money'. These essential properties are entirely functional. As Hicks puts it, "Money is defined by its functions ... money is what money does" (Hicks, 1967, 1). The explanation is that agents try to minimise uncertainty relative 
to whatever plays the functional role of money. Therefore, the explanation does not rely on any mystical powers of dollar bills. Rather, the work is done by the functional analysis of money.

As a first approximation, the functional role money plays is that it is a medium of exchange. Keynes does not think this is quite the essential property; rather he says that money is essentially 'liquid', and perceived to be liquid. This means that if we hold money we are in a position to discharge obligations and make new purchases as they seem appropriate with greatest convenience and least cost. Even this is not what is given as the official essential property of money. To make the proof that demand for money is not demand for labour easier Keynes takes the essential properties of money to be its negligible elasticities of production and substitution. However, he makes clear that these are important because of their close connection to liquidity (GT:241). Indeed, when he comes to define a non-monetary economy, he simply defines it as one where there is no good such that the benefits it confers via its liquidity, its 'liquidity premium' exceeds the carrying costs of the good. So the properties of having a negligible elasticity of production and substitution seem necessary but insufficient for something to be money.

The reason that money uncertainty is more problematic than widget uncertainty is just that money is liquid. At the end of the day, the point of holding investments, bonds or money is not to maximise the return in terms of such units; it is to be used somehow for consumption. Hence, we prefer, ceteris paribus, to store wealth in ways that can be easily exchanged for consumption goods as and when required. Further, we may be about to come across more information about productive uses for our wealth, and if we do, we would prefer to have the least inconvenience about changing how we use wealth. Money is going to be the best store of wealth for each of these purposes. The strength of these preferences determines the liquidity premium that attaches to money.

So Keynes's story here is essentially a 'missing markets' story. If there were markets for every kind of transaction there would be no liquidity premium attaching to money, and hence no reason to be averse to uncertainty in terms of money returns as opposed to uncertainty in terms of X's shares returns. There is a methodological difference here between decision theorists and economists. In decision theory it is common to specify what choices an agent does have. These will usually be finite, or at least simply specified. In economics it is more common to specify what choices an agent does not have, which markets are 'missing'. In a sense the difference is purely cosmetic, but it can change the way problems are looked at. Since Keynes requires here some markets to be missing, it might be worth investigating what happens here from the more restrictive framework ordinarily applied in decision theory.

In some decision-theoretic contexts, we can prefer liquidity even when we are completely certain about what our choices are and what their outcomes will be. Say we are in a game where the object is to maximise our money over 2 days. We start with $\$ 100$. On day 1 , we have a choice of buying for $\$ 100$ a ticket that will pay $\$ 200$ at the end of day 2 , and is non-transferable, or doing nothing. On day 2, if we still have our $\$ 100$, we can buy with it a voucher which pays $\$ 300$ at the end of day 2 , or do 
nothing. Obviously, the best strategy is to do nothing on day 1 , and buy the voucher on day 2. The point is just that money here has enough of a liquidity premium on day 1 that we are prepared to hold it and earn no interest for that day rather than buy the ticket (or two day bond) which will earn interest. So uncertainty is not a necessary condition for liquidity premia to exist. On the other hand, perhaps it is necessary for liquidity premia to exist in a world something like ours, where agents neither have all the choices they would have in a perfect market, nor as few as in this simple game. If we added a market for tickets and vouchers to our simple game the prices would be fixed so that money would lose its liquidity premium. Keynes suggests something like this is true for the worlds he is considering: "uncertainty as to the future course of the rate of interest is the sole intelligible explanation of the type of liquidity preference [under consideration]" (GT: 201). However here he merely means lack of certainty; there is no proof that if every agent had precise credences liquidity preference ought to disappear. So it looks like uncertainty in the sense discussed here, vague reasonable beliefs, does no theoretical work. Perhaps this is a bit quick, as the little game I considered is so far from a real-life situation. So I will look more closely at the effects uncertainty is supposed to have. Since it has received the bulk of the theoretical attention, I start with the indirect effects of uncertainty.

\section{Uncertainty and Liquidity Preference}

Keynes thinks the question of why money is demanded at all, why we do not all move from holding money into holding debts as soon as the rate of interest goes positive, needs answering. And he thinks the answer here will be particularly relevant to theories about the rate of interest. If the market in general is at equilibrium then the market in trades between any two goods must also be in equilibrium; in particular it cannot be that there are people holding money who would be prepared to buy debts at the current interest rate. So if the equilibrium interest rate is positive, there must be some people who would prefer to hold money than hold debts. This fact Keynes takes to be central to the correct theory of the rate of interest. Hence, to determine what the rate of interest will be, and what will cause it to change, I need to determine what causes a demand for money.

Keynes distinguishes four motives for holding money (GT: Ch. 13; (Keynes, 1937a, 215-223)). Two of these, the transactions motive and the finance motive, need not detain us. They just relate to the need to make payments in money and on time. The third, the speculative motive, is often linked to uncertainty, and indeed Keynes does so (GT: 201). But 'uncertainty' here is just used to mean absence of certainty, that is the existence of risk, which as noted above is not how I am using 'uncertainty'. As Runde (1994b) points out, an agent who is certain as to future movements in interest rates may still hold money for speculative reasons, as long as other agents who are not so certain have made mistaken judgements. The fourth motive will hold most of my attention. Keynes argues that we may hold money for purely precautionary reasons.

To provide for contingencies requiring sudden expenditure and for un- 
foreseen opportunities of advantageous purchases, and also to hold an asset of which the value is fixed in terms of money to met a subsequent liability fixed in terms of money, are further motives for holding cash (GT: 196).

Davidson $(1988,1991)$ justifies this as follows. Uncertainty arises whenever agents do not have sufficient knowledge to calculate the numerical probability of an event. This is given a rather frequentist gloss in Davidson, but that is not necessary. His idea is that we know what the probability of $p$ is when we know the frequency of $p$-type events in the past and we know the future will resemble the past in this respect. The latter is cashed out as saying $p$ is governed by an 'ergodic process'. We can replace all this by saying that $p$ is subject to uncertainty whenever we do not know its objective chance, whether or not objective chance ought to be analysed by frequentist approaches. Davidson then argues that since for most $p$ we do not have this knowledge, we have to adopt 'sensible' approaches like holding money.

Runde (1994b) objects that Davidson's story is incoherent. On Davidson's theoretical story there are only two epistemic states relative to $p$ that are possible. An agent can know the chance of $p$, in which case their credence is set equal to it, or they are completely uncertain about it. In the latter case there can be no reason for taking some action rather than another. Now the reason that it is 'sensible' to hold money is that we expect money to be liquid. However, we do not know the chance of money remaining liquid; whether or not money remains liquid is not determined by an ergodic process. Hence, we have no reason for letting that partial belief be a guide to action.

This is a fair criticism, but it can be met by amending the theory rather than by giving it up. On my theory, if an agent knows the chance of $p$ they will have a precise degree of belief in $p$. When they do not their degree of belief will, in general, be vague but not totally vague. As with Keynes, I have uncertainty come in degrees. This amendment is enough to rescue Davidson's theory. An agent might not know the chance that money will become illiquid in the next short period of time, but they might know enough for it to be reasonable to have a credence in that proposition which is vague over some small interval close to zero. It may still be sensible to hold some money even when the expected return on other investments really is vague. But is it sensible to prefer fixed to uncertain returns? In other words, is there a direct effect of uncertainty that makes people prefer bonds to investments?

\section{Uncertainty and Indecision}

As Keynes repeatedly stressed, investment is not like a game of chance where the expected results are known in advance. And this is part of the explanation for the extreme instability in investment levels compared to other economic variables.

The state of long-term expectation ... does not solely depend on the most probable forecast we can make. It also depends on the confidence with which we make this forecast (GT: 148). 
Human decisions affecting the future, whether personal or political or economic, cannot depend on strict mathematical expectation, since the basis for making such calculations does not exist ... it is our innate urge to activity which makes the wheels go round, our rational selves choosing between the alternatives as best we are able, calculating where we can, but often falling back for our motive on whim or sentiment or chance (GT: 162-3).

The most charitable reading of Keynes here is to say he agreed, in principle, with what is sometimes referred to as a Horwitz-style decision rule. If the expected return of an investment is vague over $[\alpha, \beta]$ then its 'value' is given by $(1-\rho) \alpha+\rho \beta$, where $\rho \in[0,1]$ is a measure of confidence. By the 1937 article, he has become more interested in the special case where confidence has collapsed and $\rho$ is approaching 0 . This interpretation would explain all his references to decision-making under uncertainty in The General Theory and subsequent discussion, provided we make the safe assumption that 'cold calculation' would only have us spend $x$ on an investment with expected return $[\alpha, \beta]$ when $\alpha \geq x$. In particular, any interpretation of the underlying decision theory here will have to give some role to 'whim or sentiment or chance', and I give it a variable, ' $\rho$ '. With this theory, I have the extensions needed to avoid Runde's objection to Davidson. I have a continuum of degrees of uncertainty, rather than a raw dichotomy, and I have an explanation of why it is 'sensible' to prefer gambles with known expected returns, at least when $\rho$ is relatively low.

This theory is meant to serve two related purposes. It is meant to show why we might prefer money to debts, even though our best estimate of the expected return of the debts is positive, and again it is meant to show why we might prefer debts to investments even when our best estimate of the expected return of the investment is higher. And I think if the decision rule stipulated were plausible, it would show that uncertainty did have an economic effect. In particular, I think it would show both that in times of crises when $\rho$ heads down, the level of investment will decrease even with other things being equal, and that collective action can be justified even when individual action is not. That is, the government can make sets of investments that are expected to be profitable although none of the individual investments is expected to be profitable.

The decision theory does not, however, seem plausible. First, there are some technical problems for this theory. The problem is that if $\rho<\frac{1}{2}$, then in cases where uncertainty is guaranteed to increase in the near future agents following this rule will make decisions they are sure to regret. For example, assume an agent with $\rho=\frac{1}{3}$ now has credence $\frac{1}{2}$ in $p$, but knows that some evidence will come in such that her credence in $p$ will become vague over $[0.3,0.7]$ whatever the result of the experiment. As we saw in the case of poker players, this is plausible in some situations. The agent will now pay 50 cents for a bet which pays $\$ 1$ if $p$ and nothing otherwise, but after the evidence comes in she'll sell that bet for about 44 cents, incurring a sure loss. I leave it to the reader to judge the importance of these technical problems, given the rarity of cases where uncertainty is guaranteed to rise.

There is also a philosophical problem. What precisely is $\rho$ supposed to repre- 
sent? If it is some kind of belief, its effects should have been incorporated into the credences. If it is some kind of desire its effects should have been incorporated into the evaluation of each of the states. This objection could be avoided, perhaps, if Keynes was trying to argue against the theory that investors just maximise dollar expected returns. It is not entirely clear whom Keynes thinks he is arguing against at some points. If this is his enemy, he is fighting a straw man, one who is vulnerable to much simpler objections. Whoever thought that all investment is profit driven, that no one ever went into business because they thought it would be fun to run a newspaper? Keynes's only viable opponents here are saying that investors calculate the expected return, in utils, of each possible investment and choose the one whose returns are highest. Now perhaps for many dollar returns are the most important factor in determining util returns, but this is certainly not the only cause.

If $\rho$ represents something which is neither a belief nor a desire, then it is hard to see what effect it could have on action. Perhaps there are some exceptions to the rule that actions are caused only by beliefs and desires combining in the right way, such as actions caused by values, but these appear irrelevant to Keynes's considerations, and he does not appeal to such exemptions. After all, he describes investment decisions made where the 'cold calculations' do not determine what should be done as being made by 'whim or sentiment or chance'. Now whims and sentiments are surely desires, although chance is in a different boat. If he had just said 'chance' here he may have committed himself to a different decision theory, one where the agent can under uncertainty make any decision which is not known to be sub-optimal. But this does not justify the conclusion that uncertainty decreases investment; under that theory it is random whether uncertainty increases or decreases investment. Hence Keynes appears to be implausibly committed to a mental state which is neither a belief nor a desire but affects action.

It might be objected here that I am relying on an overly individualistic theory of motivation; that what Keynes is committed to is nothing more than what anyone who has learned the difference between Robinson Crusoe economics and real-world economics would believe. There is an important truth behind this objection: the social causes of action cannot be overlooked. But this is not what I have done. The core assumption I made is that the only mental states relevant to action are beliefs and desires. Now the beliefs and desires that are relevant may not be (directly) concerned with the action at hand; they may be beliefs and desires about how society will view this action, or about similar actions which may or may not be performed by other members in society. And the beliefs and desires may not have as their immediate cause careful inference by the agent in question; they may be caused by the wave of panic or optimism in which the agent is caught up. In the real world, agents do not always change their beliefs and desires by reflection on new evidence, often emotion plays a larger role. So society has both evidential and non-evidential effects on action. But every time, the causal chain goes via the beliefs and desires of the agent. Society causes actions by causing changes in the beliefs and desires of individuals. It is wrong to think that action is never caused by beliefs and desires about society, it is wrong to think that society never directly causes beliefs and desires which lead to action, 
but none of this implies that there can be mental states other than belief and desire relevant to action.

\section{Disquietude}

There are some comments from Keynes that suggest this reading is a little unfair. Rather than having a distinctive decision theory, he perhaps has a distinctive theory about what ought enter into the decision-theoretic calculations. The standard theory for why there is a demand for insurance is the falling marginal utility of money. Agents purchase insurance, and accept a lower expected dollar return because with insurance their expected util return, at the end of the duration of the insurance, is higher than if they had not purchased. This is the story given in, for example, Freidman and Savage (1952) where the existence of demand for insurance is taken as evidence for the declining marginal utility of money. But there is another reason agents might buy insurance. They might simply feel happier, over the duration of the insured period, knowing that they have insurance and are hence exposed to fewer risks or uncertainties than otherwise. If this is true then their expected 'wealth' in both dollars and utils at the end of a period might be lower if they insure than if otherwise, but it will be worthwhile because of the benefits during the period. Keynes suggests that this same desire for quietude can cause a demand for money. I presume, though it is not entirely clear, that this desire should be included within the precautionary motives for holding money.

There are not two separate factors affecting the rate of investment, namely, the schedule of the marginal efficiency of capital [the expected return of investments] and the state of confidence. The state of confidence is relevant because it is one of the major factors determining the former (GT: 149).

For the fact that each individual investor flatters himself that his commitment is "liquid" ... calms his nerves and makes him much more willing to run a risk (GT: 160).

The possession of actual money lulls our disquietude; and the premium which we require to make us part with money is the measure of the degree of our disquietude (Keynes, 1937b, 116).

A liquidity premium ... is not even expected to be rewarded. It is a payment, not for the expectation of increased tangible income at the end of the period, but for an increase sense of comfort and confidence during the period (Keynes, 1938, 293-294).

This explanation of the demand for certain returns is in some ways conservative and some ways radical. It is conservative because it does not immediately change the technical properties of preference. Many heterodox theories of preference drop such theoretical restrictions as transitivity of preferences. By contrast the theory Keynes appears to be advocating is it least in principle conservative on this front. Agents 
are still going round maximising expected utility, just now it is expected utility over a period, not at the end of the period.

But it is not all conservative. If we explain economic decisions in terms of the disquietude of the investor we discard the distinction between investment and consumption. It was always known that there were some goods that were not comfortably categorised, particularly cars, but this move makes every good in part a consumption good. If all this meant was that some helpful classifications have to be questioned, it would not be important. Rather, its importance flows from its implications for the norms for investment. It is always irrational to make an investment which will incur a sure loss. This principle is used to derive wide-ranging implications for decisiontheory. But it is not irrational to make a consumption decision which will result in sure loss at the end of a period in exchange for goods during that period. It is not always irrational to pay ten dollars for a movie ticket, even though this will incur a sure loss in the sense the buyer will surely have less wealth at the end of the movie than if they had not bought the ticket.

Given this, the technical complaint I raised against the Horvitz-style decision rule misses the target. And the philosophical concern about what $\rho$ represents is irrelevant. If the expected returns only measure how much various gambles will be worth at the end of the period, then some desires have not yet been included in our calculations. That is, $\rho$ represents some desires but the theory is not guilty of doublecounting. So far this all seems to work, and explain the role of uncertainty. Indeed, I think this is the best extension of Keynes's views in this area.

While there seem to be few theoretical objections which can be raised at this point, there is a rather telling empirical objection. The only role given to disquietude in this theory is in deciding between alternatives where the returns on at least one are uncertain. But it seems implausible that disquietude could have this effect, but have no effect when choices are being made between alternatives where at least one is risky. I doubt the feelings of disquiet would be any different were I to have a large fortune riding on a roulette wheel or a baseball game. Disquietude arises because we do not know what will happen; maybe for some people it is greater when we do not know the expected returns, but I doubt it. Again, perhaps there is an explanation for demand for money in the real world to be found here, but uncertainty plays no role in the story, or at best a small cameo.

\section{Summary}

Keynes argued that uncertainty has a major economic impact. By driving people to store their wealth in ways with more stable returns, it increases the demand for cash and decreases the demand for investments. Not only does it drive down investments in this direct way, the increased demand for cash leads to higher interest rates and hence people are driven out of investment into bonds. However, there are a few problems with the story. First, the motivation for demanding returns fixed with respect to a certain good can only be that the markets between that good and other goods are more complete. But if that is the case there is a reason to demand that good even when the world is completely certain. Secondly, the only decision-theoretic 
justification for this demand for fixed returns could be the disquiet generated by not knowing the return. This follows from the formalisation of uncertainty advocated in sections 1 and 2. But this disquiet could just as easily be generated by risk as by uncertainty. So Keynes has not shown that uncertainty has any particular economic impact. That's the bad news. The good news is that many of the arguments seem to work without the reliance on uncertainty.

\section{References}

Bateman, Bradley, (1996). Keynes's Uncertain Revolution. Ann Arbor: University of Michigan Press. (4)

Carnap, Rudolf, (1950). Logical Foundations of Probability. Chicago: University of Chicago Press. (6)

Coates, John, (1996). The Claims of Common Sense. Cambridge: Cambridge University Press. (4)

Davidson, Paul, (1988). "A Technical Definition of Uncertainty and the LongRun Non-neutrality of Money." Cambridge Journal of Economics 12: 329-338, doi:10.1093/oxfordjournals.cje.a035063. (13)

-, (1991). "Is Probability Theory Relevant for Uncertainty? A Post Keynesian Perspective." Journal of Economic Perspectives 5: 129-144, doi:10.1257/jep.5.1.129. (13)

Davis, John, (1994). Keynes's Philosophical Development. Cambridge: Cambridge University Press. (4)

Dempster, Arthur, (1967). "Upper and Lower Probabilities induced by a Multi-valued Mapping." Annals of Mathematical Statistics 38: 325-339, doi:10.1214/aoms/1177698950. (4)

van Fraassen, Bas, (1990). "Figures in a Probability Landscape." In J. M. Dunn and A. Gupta (eds.), Truth or Consequences, 345-356. Amsterdam: Kluwer. (2)

Freidman, M. and Savage, L., (1952). "The Expected Utility Hypothesis and the Measurability of Utility." Journal of Political Economy 60: 463-474, doi:10.1086/257308. (16)

Gärdenfors, Peter and Sahlin, Nils-Eric, (1982). "Unreliable probabilities, risk taking and decision making." Synthese 53: 361-386, doi:10.1007/bf00486156. (2)

Hart, A. G., (1942). "Risk, Uncertainty and the Unprofitability of Compounding Probabilities." In F. McIntyre O. Lange and T. O. Yntema. (eds.), Studies in Mathematical Economics and Econometrics, 110-118. Chicago: University of Chicago Press. (2)

Hicks, John, (1967). Critical Essays in Monetary Theory. Oxford: Clarendon Press. (10) 
Jaffray, J. Y., (1994). “Decision Making with Belief Functions.” In Yager et al. (1994), 331-352. (9)

Jeffrey, Richard, (1983). “Bayesianism with a Human Face.” In J. Earman (ed.) (ed.), Testing Scientific Theories. Minneapolis: University of Minnesota Press. (2)

Keynes, John Maynard, (1921). Treatise on Probability. London: Macmillan. (4, $5,6)$

-, (1936). The General Theory of Employment, Interest and Money. London: Macmillan. $(1,2,7)$

-, (1937). "The Ex Ante Theory of the Rate of Interest." Economic Journal 47: 663668, doi:10.2307/2225323. Reprinted in (Keynes, 1989, XIV 215-223), references to reprint. (12)

-, (1937). "The General Theory of Employment." Quarterly Journal of Economics 51: 209-223, doi:10.2307/1882087. Reprinted in (Keynes, 1989, XIV 109-123), references to reprint. $(2,7,9,10,16)$

Keynes, John Maynard (1938). Letter to Hugh Townshend dated 7 December, 293294. Volume 14 of Keynes (1989). Edited by D. E. Moggridge. (16)

—, (1971-1989). The Collected Writings of John Maynard Keynes. London: Macmillan. Edited by D. E. Moggridge. (19)

Levi, Isaac, (1980). The Enterprise of Knowledge. Cambridge, MA.: MIT Press. (2, 9)

—, (1982). "Ignorance, Probability and Rational Choice." Synthese 53: 387-417, doi:10.1007/bf00486157. (2)

Ramsey, Frank, (1926). “Truth and Probability.” In D. H. Mellor (ed.), Philosophical Papers, 52-94. Cambridge: Cambridge University Press. (5)

Runde, Jochen, (1990). "Keynesian Uncertainty and the Weight of Arguments." Economics and Philosophy 6: 275-293, doi:10.1017/s0266267100001255. (6)

-, (1994). "Keynes After Ramsey: In Defence of 'A Treatise on Probability'." Studies in the History and Philosophy of Science 25: 97-124, doi:10.1016/00393681(94)90022-1. (4)

—, (1994). "Keynesian Uncertainty and Liquidity Preference." Cambridge Journal of Economics 18: 129-144, doi:10.1093/oxfordjournals.cje.a035266. (12, 13)

Shafer, Glenn, (1976). A Mathematical Theory of Evidence. Princeton: Princeton University Press. (4)

Shapiro, Nina, (1997). "Imperfect Competition and Keynes." In G. C. Harcourt and P. A. Riach (eds.), A 'Second Edition' of the General Theory, volume 1, 83-92. London: Routledge. (1) 
Strat, Thomas, (1990). "Decision analysis using Belief Functions." International Journal of Approximative Reasoning 4: 391-417, doi:10.1016/0888-613x(90)90014s. (9)

Tintner, Gerhard, (1941). "The Theory of Choice Under Subjective Risk and Uncertainty.” Econometrica 9: 298-304, doi:10.2307/1907198. (2)

Walley, Peter, (1991). Statisical Reasoning with Imprecise Probabilities. London: Chapman \& Hall. $(1,2,4)$

Yager, R., Fedrizzi, M., and Kacprzyk, J. (eds.), (1994). Advances in the DempsterShafer Theory of Evidence. New York: John Wiley. $(4,19)$ 